\title{
Use of simulation technology in teaching nursing clinical skills
}

\section{Michael Kourakos}

Department of Nursing, ‘Asklepieion' Voulas General Hospital, Athens, Greece

Email: mixkourakos@hotmail.com

\section{Theodora Kafkia*}

Faculty of Nursing,

Alexander Technological Educational Institute,

Thessaloniki, Greece

Email: dkafkia@hotmail.com

*Corresponding author

\begin{abstract}
Nursing education has evolved from being descriptive and more conventional to using state-of-the-art equipment such as simulators and/or computer software. Educational institutions invest in costly technology in order to prepare students for clinical practice while not worrying for patient's safety and confidentiality. On the other hand, educators need to be able not only to use modern technology, but also to prepare appropriate and active learning courses transforming students from passive receptors of knowledge to critical thinkers who can apply their theoretical knowledge in the actual clinical or community setting. The goal of high-fidelity technologies integration into education is to achieve high level and cost-effective care and ultimate patient outcomes.
\end{abstract}

Keywords: education; nursing; simulation.

Reference to this paper should be made as follows: Kourakos, M. and Kafkia, T. (2020) 'Use of simulation technology in teaching nursing clinical skills', Int. J. Entertainment Technology and Management, Vol. 1, No. 1, pp.95-102.

Biographical notes: Michael Kourakos is the Head of the Department of Nursing, 'Asklepieion' Voulas General Hospital, Athens, Greece. He has a 30 years clinical career in nursing care and nursing administration. In the last five years he has taught either in undergraduate (ATEI of Thessaloniki, TEI of Crete) and postgraduate level (University of Western Attica). He has published a lot in Greek and English. His main interests are renal and mental health nursing, education, evidence-based nursing and administration.

Theodora Kafkia is an Assistant Professor in the Faculty of Nursing in the ATEI of Thessaloniki. She has a 20 years clinical background and is a full time Professor since 2013, teaching in undergraduate and post-graduate nursing programs. Her interests are renal nursing, education, evidence-based practice, diabetes mellitus and quality of life. She has published a lot in Greek and English and she has been a member of the Education and Research Board (2003-2012), as well as the Accreditation Committee (2019) of the European Dialysis and Transplantation Nursing Association. 


\section{Introduction}

Nowadays, a lot of educational institutions invest in simulation technology for providing state-of-the-art teaching. According to Merriam-Webster's Dictionary (2018), simulation is defined as "the imitative representation of the functioning of one system or process by means of the functioning of another." Another definition of the word, also included in the same dictionary, states that simulation is the "examination of a problem often not subject to direct experimentation by means of simulating device."

The first use of the simulation process has been recorded to be in World War II during pilot training (Ward-Smith, 2008). The process is still used to train pilots in very sophisticated simulators using scenarios of poor weather conditions, loss of power and engine failures aiming at achieving higher safety both for commercial and military flights. Furthermore, the aviation industry is using flight simulators to imitate exact weather and flight conditions after plane accidents to determine the reasons and to try to prevent other accidents. Another major user of such technologies is the motor industry. Car manufacturers and research institutes are using simulation in order to set standards for passenger safety, testing seatbelts and car breaks, as well as the whole car's response to various weather conditions or coalition situations.

In everyday life, simulation is a very popular form of entertainment since the first video games, in the mid-1980s, were released. They were designed to simulate real-world activities, such as farming, driving, doing a sport or business, planning strategies and military operations (Wolf and Baer, 2001). Modern simulation games are using sophisticated and high-fidelity graphics that are very life-like. In addition, virtual reality equipment can be connected to home cinemas, TVs or computers giving the player the ability to be a part of the game.

As science and technology progressed, simulation has been adopted by education as sophisticated and innovative learning and teaching approach, as well as an assessment practice (Edgecombe et al., 2013; Zendejas et al., 2013). In healthcare education, in particular, the USA Institute of Medicine, in 2004, has adapted simulation as a pedagogical method and proposed the use of it by healthcare schools (Sanford, 2010). The use of sophisticated advanced technological devices, such as simulator rooms and/or computerised mannequins that perform human functions realistically, are allowing students, as well as professionals that want to update their knowledge, to practice skills and interventions in a more 'artificial' and less threatening environment of a lab to provide accurate and safe care to patients/clients (Sanford, 2010; Arthur et al., 2012). With simulation real situations can be mirrored, anticipated or amplified with guided experiences in a completely interactive way. Within this context "simulation is a technique to replace or amplify real experiences with guided experiences, often immersive in nature, that evoke or replicate substantial aspects of the real world in a fully interactive fashion" (Gaba, 2007). Simulation can be of high or low cost, depending on the technology, fidelity, and methods used (Maloney and Haines, 2016). During the simulation process professional actors or mannequins can be used in live or 'virtual' environments presenting any signs, symptoms, and feelings an actual patient would feel (Maloney and Haines, 2016).

In Greece, mainly due to financial constraints and reduced budgets, the majority of nursing schools are not fully equipped with high-fidelity simulation technology. Clinical skills are practiced mainly on models or mannequins with the use of clinical scenarios and care plans and afterward in the actual clinical environment. Having that in mind, the 
present review is the first part of a research study on the impact and effectiveness of high-fidelity simulation technology into nursing education and clinical skill teaching.

A literature review was conducted in the last five year's publications in PubMed and CINAHL, in order to find studies on the use and effectiveness of simulation in nursing education and the impact on student learning. Keywords used in the search were nursing education and simulation, clinical skill teaching and simulation, learning in clinical environment, undergraduate nursing studies and simulation. More than 300 papers were found and from those 100 matched the search criteria.

\section{Nursing education and simulation technology}

Nursing teaching process within nursing curricula integrates theoretical knowledge and practical skills aiming at preparing students to develop their problem-solving skills and implement them in real-time situations during their clinical placement and/or their career (Norman, 2012).

Organised nursing education has started with classroom lectures by an experienced nurse, teaching, mainly empirically, nursing interventions and implementing them directly to patients/clients. It proceeded to more theoretical courses but still, procedural skills had to be learned with the use of learning equipment such as oranges to practice intramuscular and subcutaneous injections. Life-size mannequins and task trainers (part or region of the body) were introduced in nursing education in the early 1910s, in the USA and Canada, and became more popular worldwide in the 1950s (Hyland and Hawking, 2009). The outer layer became more sophisticated, but it was still rubber and gave no actual human skin feeling making difficult for students to visualise this dummy model as a real person with health problems (Issenberg et al., 2001; Seropian et al., 2004; Medley and Horne, 2005).

Since the late 1990s and the early 2000s, various simulation educational methods, useful pedagogical approaches, were used according to education level and learning outcomes without compromising the patient's safety or well-being (Toserud et al., 2013; Kim et al., 2016). Up-to-date nursing education uses devices, equipment and computer software specially designed to imitate patient's signs, symptoms and reactions looking like life-sized human mannequins but with extremely realistic anatomical structure and high response fidelity (Issenberg et al., 2005; Kiernan, 2018). The 'patient' can have a pulse and heartbeat, signs of bleeding or fluid overload and the healthcare student can perform auscultation of heart, lung and bowel sounds. Low-fidelity basic simulators, such as wound sites, model 'arm' for practicing IV insertion, Foley insertion pelvic models, are also used in a lot of training settings (Hyland and Hawkins, 2009; Sanford, 2010). Furthermore, lifelike virtual clinical environments (emergency room, operating theatre, hospital ward and community settings) and/or emergency situations are used to help nursing students to develop a variety of skills that are going to be needed during their career (Moule et al., 2008; MacLean et al., 2018). In addition, with the use of computers students can develop not only clinical skills, but also procedures that are used in everyday clinical practice like patient handoffs, phone assessment and provision of guidelines or teaching self-management to a patient aiming at improving patients' outcomes (Kraft et al., 2013; Kiernan, 2018). 
An in-depth literature review by Paige and Morin (2013) described simulation as a matrix of three dimensions: physical, psychological and conceptual. Physical dimension is associated with equipment (mannequin technology) and environment (appearance and layout of the simulated setting). Psychological dimension is about students' perceptions about the believable representation and authenticity of the experience of caring for a 'real' patient. The conceptual dimension refers to the way that theoretical knowledge is connected to the clinical situation encountered during the simulation process.

In the evolving of nursing education, members of the faculty are teaching students to become critical thinkers who can apply their evidence-based theoretical knowledge and clinical skills in complex healthcare situations (Decker et al., 2008; Welman and Spies, 2016). A US national survey (Clapper and Kardong-Edgren, 2012) has demonstrated that $69 \%$ of nursing teachers' time is consumed by observing students demonstrating clinical skills. Worldwide, and in Greece in particular, patients' shorter hospitalisation days, larger student numbers and faculty shortage, due to financial cut-outs in universities' budgets, have led to fewer clinical practice hours than a decade ago. Because of the situation described, students are not able to have the appropriate supervised clinical experience (Rhodes and Curran, 2005; Missen et al., 2016). On the other hand, patient numbers are increasing, diseases become chronic and more complex as the world's population is aging, making the demand for better-prepared healthcare students urgent (Nestel and Kneebone, 2010). A solution to the problem could be the use of simulation during graduate studies where faculty can teach and evaluate student clinical skills and then students could have clinical practice without the need for intense supervision by their teachers (McCormick et al., 2010; Nestel and Kneebone, 2010). Alas, only two nursing schools out of nine Greek universities and applied universities have the privilege to have high-fidelity equipment/mannequins and none a simulation classroom or environment.

\section{Advantages and disadvantages of simulation as an educational strategy}

Training healthcare professionals with simulation, according to DeVita (2009), should be the main educational strategy as it is "measurable, focused, reproducible, mass producible and very memorable." As a teaching process, simulation offers a means through which students participate in clinical decision-making and provision of care in a manner not encouraged by merely reading textbooks or listening to lectures. It includes first self-study or classroom lecture, secondly the simulation session and finally an evaluation session. In the last phase of simulation teaching, evaluation, students review their performance and discuss the theoretical framework that was applied into the nursing practice scenario (Fowler Durham and Alden, 2008). The most important part of the whole process is the feedback that the instructor/teacher is giving at the end of the evaluation session.

Scholars have been looking into the use of sophisticated technology combined with traditional ways of teaching nursing science and skills. In the mid-1990s, the beginning of the high-fidelity simulation, Fletcher (1995) argued about its positive effects: realistic clinical settings, no threat to the patient, active learning, errors that could be corrected and discussed, and consistent experience offered to all the students. In other words, 
simulation is a mixture of technical and non-technical experiences and skills that are offered to all students (Medley and Horne, 2005; Nestel and Kneebone, 2010).

Since the beginning of the 2010s, it is well established that the advantages of simulation-based education include the ability to repeat the nursing skills taught, to provide feedback, to adjust the difficulty level, to individualise learning, to improve communication skills and collaboration and enhance self-efficacy (Kim and Choi, 2011; Cook et al., 2011; Kim et al., 2011; Norman, 2012; Kraft et al., 2013). Furthermore, students have been found to be more active in the classroom, more satisfied by their ability to implement knowledge into practice, keener to the learning process and faster learners than those who were trained with traditional education practices (Garrett et al., 2010; Norman, 2012; Shin et al., 2015). Kim et al. (2016) argue that simulation-based nursing education has a positive educational effect, especially in students' psychomotor domain.

In addition, as it has been documented that nursing students and new graduate nurses with less than a year of clinical experience are involved in $49 \%-53 \%$ of patient falls, medication administration errors and failure-to-rescue incidents simulation training can prevent these situations (Saintsing et al., 2011; Beroz and Hallmark, 2017; Kenward and Zhong, 2006). Repetitive supervised practice with critique and feedback from faculty embedded into virtual reality simulator helps students to become more competent in clinical skills and enhance their performance (Oermann et al., 2011; Chiniara et al., 2013).

On the other hand, it could be argued that technology has an uneven effect on teachers and students, based on their familiarity, comfort, and expertise with technology, and their intent of how to use technology. It is well established that every new generation can understand and use technology better than the previous one (Canas-Bajo et al., 2016). So, it not uncommon that nursing students can use sophisticated devices easier and more efficient than faculty members. McKnight et al. (2016) stated that current learners expect their faculty to use technology in education and to incorporate the modern technologies needed for their profession. In addition to that, science textbooks tend to be outdated by the time they reach students and the combined use of other resources can provide richer and more useful information (McKnight et al., 2016).

In order to keep up with training needs and trends in education, a lot of nursing schools have purchased extremely costly interactive computerised models and/or setup simulation training classrooms. However, it is not uncommon that the teaching process is still unchanged, and the equipment misused or underused mainly due to faculty's difficulty in dealing with such equipment and the resistance to change (Medley and Horne, 2005). In addition, this enormous emphasis on having state-of-the-art equipment and surroundings, might negatively affect the learning outcomes (Dieckmann et al., 2009), as students could be more interested and keen on practicing in the safety of the simulation lab than in actual clinical settings.

With more innovation in nursing education, and with appropriately trained personnel, knowledge and skills offered to reach a higher level aiming at providing a better quality of care for patients/clients. Nurse educators through simulation technology, as well as other new teaching procedures, can bring transformational leadership to the profession and achieve the goal of a high level and cost-effective care and ultimate patient outcomes. 


\section{Conclusions}

Today, simulation technology is more mainstream than ever; but is it worth the financial cost? In our opinion, it is a value for money investment. Learners can have up-to-date scientific knowledge and clinical skills, interprofessional collaboration with fewer educators, in a safe, but also accurate, clinical and/or community environment where confidentiality and safety concerns cannot interfere with the teaching process.

For nursing students, and other healthcare professionals, to be clinically competent and confident it is required of them to spent adequate time practicing in the lab and get sufficient feedback on techniques and performance. Simulation training can enhance a student's confidence, critical thinking, knowledge, and skills leading to the creation of a better healthcare professional.

\section{References}

Arthur, C., Levett-Jones, T. and Kable, A. (2012) 'Quality indicators for design and implementation of simulation experiences: a Delphi study', Nurse Education Today, Vol. 33, No. 11, pp.1357-1361.

Beroz, S. and Hallmark, B. (2017) Academia to Bedside: What We Know Now, NLN Center for Innovation in Simulation and Technology (NLNTEQ) [online] https://nlnteq.org/2017/05/16/ academia-tobedside-what-we-know-now-part1/ (accessed 01/06/2018).

Canas-Bajo, J., Leikas, J., Jokinen, J., Canas, J. and Saariluoma, P. (2016) 'How older and younger people see technology in Northern and Southern Europe: closing the generation gap', Gerontechnology, Vol. 14, No. 2, pp.110-117.

Chiniara, G., Cole, G., Brisbin, K., Huffman, D., Cragg, B., Lamacchia, M. and Norman, D. (2013) 'Simulation in healthcare: a taxonomy and a conceptual framework for instructional design and media selection', Medical Teacher, Vol. 35, No. 8, pp.e1380-1395, Canadian Network for Simulation in Healthcare Guidelines Group.

Clapper, T.C. and Kardong-Edgren, S. (2012) 'Using deliberate practice and simulation to improve nursing skills', Clinical Simulation Nursing, Vol. 8, No. 3, pp.e109-e113.

Cook, D., Hatala, R., Brydges, R., Zendejas, B., Szostek, J., Wang, A., Erwin, P. and Hamstra, S. (2011) 'Technology-enhanced simulation for health professions education: a systematic review and meta-analysis', Journal of American Medical Association, Vol. 306, No. 9, pp.978-988.

Decker, S., Sportsman, S., Puetz, L. and Billings, L. (2008) 'The evolution of simulation and its contribution to competency', Journal of Continuing Education in Nursing, Vol. 39, No. 2, pp.74-80.

DeVita, M.A. (2009) 'Society for simulation in healthcare presidential address', Simulation in Heathcare, Vol. 4, No. 1, pp.43-48.

Dieckmann, P., MolinFriis, S., Lippert, A. and Ostergaard, D. (2009) 'The art and science of debriefing in simulation: ideal and practice', Medical Teaching, Vol. 31, No. 7, pp.e287-e294.

Edgecombe, K., Seaton, P., Monahan, K., Meyer, S., LePage, S. and Erlam, G. (2013) 'Clinical simulation in nursing: a literature review and guidelines for practice', Ako Aotearoa, National Centre for Tertiary Teaching Excellence, Wellington, New Zealand.

Fletcher, J.L. (1995) 'Update for nurse anaesthetists-anaesthesia simulation: a tool for learning and research', Journal of the American Association of Nurse Anaesthetists, Vol. 63, No. 1, pp.61-67.

Fowler Durham, C. and Alden, K.R. (2008) 'Enhancing patient safety in nursing education through patient simulation', in Hughes, R.G. (Ed.): Patient Safety and Quality: An Evidence-Based Handbook for Nurses, Rockville, MD, USA. 
Gaba, D.M. (2007) 'The future vision of simulation in healthcare', Simulation in Healthcare, Vol. 2, No. 2, pp.126-135.

Garrett, B., Macphee, M. and Jackson, C. (2010) 'High fidelity patient simulation: considerations for effective learning’, Nursing Education Perspectives, Vol. 31, No. 5, pp.309-313.

Hyland, J. and Hawkins, M. (2009) 'High-fidelity simulation in nursing education: a review of the literature and guide for implementation', Teaching and Learning in Nursing, Vol. 4, No. 1, pp.14-21.

Institute of Medicine (2004) Keeping Patients Safe, National Academies Press, Washington, DC.

Issenberg, S.B., Gordon, M.S., Gordon, D.L., Safford, R.E. and Hart, I.R. (2001) 'Simulation and new learning technologies', Medical Teaching, Vol. 23, No. 1, pp.16-23.

Issenberg, S.B., Mc Gaghie, W.C., Petrusa, E.R., Lee Gordon, D. and Scalese, R.J. (2005) 'Features and uses of high-fidelity medical simulations that lead to effective learning: a BEME systematic review', Medical Teaching, Vol. 27, No. 1, pp.10-28.

Kenward, K. and Zhong, E. (2006) Report of Findings from the Practice and Professional Issues Survey: Fall 2004, National Council of State Boards of Nursing (NCSBN) [online] https://www.ncsbn.org/Vol_22_web.pdf(accessed 01/06/2018).

Kiernan, L.C. (2018) 'Evaluating competence and confidence using simulation technology', Nursing, Vol. 48, No. 10, pp.45-52.

Kim, H.R. and Choi, E.J. (2011) 'Development of a scenario and evaluation for SimBaby simulation learning of care for children with fever in emergency units', Journal of Korean Contents Association, Vol. 11, No. 6, pp.279-288.

Kim, H.R., Choi, E.Y. and Kang, H.Y. (2011) 'Simulation module development and team competency evaluation', Journal of Korean Academy Fundamental Nursing, Vol. 18, No. 3, pp.392-400.

Kim, J., Park, J.H. and Shin, S. (2016) 'Effectiveness of simulation-based nursing education depending on fidelity: a meta-analysis', BMC Medical Education, Vol. 16, pp.152-158.

Kraft, S., Wise, H., Jacques, P. and Burik, J. (2013) 'Discharge planning simulation: training the interprofessional team for the future workplace', Journal of Allied Health, Vol. 42, No. 3, pp.175-181.

MacLean, S., Geddes, F., Kelly, M. and Della, P. (2018) 'Simulated patient training: using inter-rater reliability to evaluate simulated patient consistency in nursing education', Nurse Education Today, Vol. 62, pp.85-90.

Maloney, S. and Haines, T. (2016) 'Issues of cost-benefit and cost-effectiveness for simulation in health professions education', Advances in Simulation, Vol. 1, pp.13-19.

McCormick, M., Burton, T. and Werts, N. (2010) 'Case scenarios and simulations as techniques to facilitate asthma education and team building among health care students', Journal of Asthma and Allergy Educators, Vol. 1, No. 1, pp.18-22.

McKnight, K., O’Malley, K., Ruzic, R., Horsley, M.K., Franey, J.J. and Bassett, K. (2016) 'Teaching in a digital age: how educators use technology to improve student learning', Journal of Research on Technology in Education, Vol. 48, No. 3, pp.194-211.

Medley, C. and Horne, C. (2005) 'Using simulation technology for undergraduate nursing education', Journal of Nursing Education, Vol. 44, No. 1, pp.31-34.

Missen, K., McKenna, L., Beauchamp, A. and Larkins, J.A. (2016) 'Qualified nurses' rate new graduates as lacking skills in key clinical areas', Journal of Clinical Nursing, Vol. 25, Nos. 15-16, pp.2134-2143.

Moule, P., Wilford, A., Sales, R. and Lockyer, L. (2008) 'Nursing student learning through simulation: a randomised study of non-equivalent groups', Nurse Education Today, Vol. 28, pp.790-797.

Nestel, D. and Kneebone, R. (2010) 'Authentic patient perspectives in simulations for procedural and surgical skills’, Academic Medicine, Vol. 85, No. 5, pp.889-893. 
Norman, J. (2012) 'Systematic review of the literature on simulation in nursing education', The ABNF Journal, Vol. 23, No. 2, pp.24-28.

Oermann, M.H., Kardong-Edgren, S., Odom-Maryon, T., Hallmark, B., Hurd, D., Rogers, N., Haus, C., Keegan McColgan, J., Snelson, C., Dowdy, S.W., Resurreccion, L., Kuerschner, D., Lamar, J., Nelson Tennant, M. and Smart, D. (2011) 'Deliberate practice of motor skills in nursing education: CPR as exemplar', Nursing Education Perspectives, Vol. 32, No. 5, pp.311-315.

Paige, J.B. and Morin, K.H. (2013) 'Simulation fidelity and cueing: a systematic review of literature', Clinical Simulation in Nursing, Vol. 9, No. 11, pp.e481-e489.

Rhodes, M. and Curran, C. (2005) 'Use of the human patient simulator to teach clinical judgment skills in a baccalaureate nursing program', CIN: Computers, Informatics, Nursing, Vol. 23, No. 5, pp.256-264.

Saintsing, D., Gibson, L.M. and Pennington, A.W. (2011) 'The novice nurse and clinical decision-making: how to avoid errors', Journal of Nursing Management, Vol. 19, No. 3, pp.354-359.

Sanford, P. (2010) 'Simulation in nursing education: a review of the research', The Qualitative Report, Vol. 15, No. 4, pp.1006-1011.

Seropian, M.A., Brown, K., Gavilanes, J.S. and Driggers, B. (2004) 'Simulation: not just a manikin', Journal of Nursing Education, Vol. 43, No. 4, pp.164-169.

Shin, S., Park, J.H. and Kim, J.H. (2015) 'Effectiveness of patient simulation in nursing education: meta-analysis', Nurse Education Today, Vol. 35, No. 1, pp.176-182.

Toserud, R., Hedelin, B. and Hall-Lord, M.L. (2013) 'Nursing students' perception of highand low-fidelity simulation used as learning methods', Nurse Education and Practice, Vol. 13, No. 4, pp.262-270.

Ward-Smith, P. (2008) 'The effect of simulation learning as a quality initiative', Urology Nursing, Vol. 28, No. 6, pp.471-477.

Merriam-Webster's Dictionary (2018) [online] https://www.merriam-webster.com/dictionary (accessed 01/06/2018).

Welman, A.M. and Spies, C. (2016) 'High-fidelity simulation in nursing education: considerations for meaningful learning', Trends in Nursing, Vol. 3, No. 1, pp.16-20.

Wolf, M. and Baer, R. (2001) The Medium of the Video Game, The University of Texas Press, Austin, USA

Zendejas, B., Wang, A.T., Brydges, R., Hamstra, S.J. and Cook, D.A. (2013) 'Cost the missing outcome in simulation-based medical education research: a systematic review', Surgery, Vol. 153, No. 2, pp.160-176. 